\title{
Mediating effects of depression on anxiety and leisure constraints in patients with breast cancer
}

\author{
Hsiu-Mei Huang ${ }^{1 \dagger}$, Jun-Hung Lai $^{2 \dagger}$ and Tsai-Wei Huang ${ }^{3,4^{*}}$ (D)
}

\begin{abstract}
Background: Patients with breast cancer often exhibit high levels of anxiety and depression and a considerable decrease in their ability to participate in leisure activities, which result in the long-term disruption of their daily lives. This study intended to explore the relationships among anxiety, leisure constraints, and depression and evaluate whether depression mediates the effects of anxiety on leisure constraints in patients with breast cancer.

Method: This prospective study included 106 patients with breast cancer. All the patients completed the Taiwanese version of the Hospital Anxiety and Depression Scale and Leisure constraints questionnaire. Path analysis was used to test the mediating role of depression.

Results: Leisure constraints, anxiety, and depression were positively interrelated and co-occurred in the patients. The accelerated bootstrapping confidence intervals of the indirect effect did not include zero (0.276-1.663). Moreover, depression completely mediated the effects of anxiety on leisure constraints in patients with earlier cancer stages but not in patients with advanced cancer stages.

Conclusions: Depression is a crucial mechanism underlying the relationship between anxiety and leisure constraints in patients with breast cancer. Although many patients experience minimal disruption of activities and roles during survivorship, they are unable to perform functional activities and satisfactorily play their roles. This is the first study to explore leisure constraints in patients with breast cancer and investigate the mediating role of depression that underlies the relationship between anxiety and leisure constraints. The current findings are clinically crucial because they suggest the need to consider the simultaneous management of anxiety and depression for alleviating leisure constraints.
\end{abstract}

Keywords: Breast Cancer, Depression, Anxiety, Leisure constraints

\section{Background}

Breast cancer is a major health threat and cause of mortality in women worldwide [1]. In Taiwan, breast cancer is the most common cancer in women and a major cause of cancer-related deaths [2]. The survival rates of patients with breast cancer have increased in recent years $[3,4]$. Psychological distress is particularly high in patients with cancer, and it adversely affects their quality of life as well as survival and recurrence rates. Patients

\footnotetext{
* Correspondence: tsaiwei@tmu.edu.tw

${ }^{\dagger}$ Dr Lai and Hsiu-Mei Huang has contributed as much as the first author

${ }^{3}$ School of Nursing, College of Nursing, Taipei Medical University, Taipei, Taiwan

${ }^{4}$ Cochrane Taiwan, Taipei Medical University, Taipei, Taiwan

Full list of author information is available at the end of the article
}

often report high levels of anxiety and depression [5]. Nearly $50 \%$ of women with early-stage breast cancer presented the symptoms of severe depression or anxiety, or both in the first year after diagnosis [6]. Another study showed that $36.7 \%$ of the patients with early-stage breast cancer experienced mood disorders (9.6, 27.1, and 8.6\% exhibited severe depression, mild depression, and anxiety, respectively) [7]. Moreover, young women who had received a new diagnosis of metastatic breast cancer experienced anxiety symptoms, although depression was less common [8]. In particular, depression has been associated with poor breast cancer survival $[9,10]$.

According to a systematic review, there was a strong association between insufficient physical activity and a

(c) The Author(s). 2019 Open Access This article is distributed under the terms of the Creative Commons Attribution 4.0 International License (http://creativecommons.org/licenses/by/4.0/), which permits unrestricted use, distribution, and 
decreased prognosis in patients with breast cancer [11]. Furthermore, physical activity interventions may alleviate psychological problems by exerting small-to-moderate beneficial effects on emotional distress and anxiety [12]. Leisure-time physical activities have a wide range of physical and mental health benefits [13, 14]. Encouraging patients to perform activities and continue leisure activities may reduce health care expenditure [15]. However, information regarding leisure constraints in patients with breast cancer and the evidence of relationships among anxiety, depression, and leisure constraints are scant.

Leisure constraint model presented by Crawford and Godbey (1987) [16] and Crawford, Jackson, and Godbey (1991) [17] have been widely adopted as crucial topics in studies on leisure behavior. This model had identified 3 major sources for leisure constraints: structural, interpersonal, and intrapersonal [18]. Structural constraints, such as financial resources, availability of facilities, availability of time, and climate, are factors that affect leisure preferences, choices, and actual participation. Interpersonal constraints are factors that affect the formation of relationships between individuals, such as failure to find suitable co-participants. Intrapersonal constraints reflect psychological states and personal characteristics such as stress, anxiety, depression, and socialization activities. In non-Western environments, few studies have investigated leisure constraints, particularly in patients with cancer [19]. So far, research on leisure constraints is still in its infancy.

Restoring the normal life and leisure activities of patients with cancer is necessary. However, psychological distress may adversely affect these patients' abilities to participate in leisure activities. Therefore, we intended to explore the relationships among leisure constraints, anxiety, and depression and investigated whether depression mediates the effects of anxiety on leisure constraint. The study hypothesized that anxiety increases the severity of leisure constraints by causing depression in patients with breast cancer.

\section{Methods}

\section{Study design and setting}

A convenience sample of women with breast cancer was recruited at a local hospital in central Taiwan. Participants selection criteria were as follows: 1) age older than 20 years; 2) had undergone breast cancer surgery, including breast-conserving surgery (BCS), modified radical mastectomy (MRM), or MRM combined with immediate breast reconstruction (IBR); 3) could communicate in Mandarin or Taiwanese. This study was approved by an institutional review board [CYCH-IRB 102060]. Written consents were obtained from the participants.

\section{Measure}

A semi-structured interview tool to collect the patients' demographic data (age, marital status, education level, income, disease information) and type of treatment received. Also, each participant completed the Hospital Anxiety and Depression Scale (HADS) and the Leisure Constraints Questionnaires (LCQ) [Additional file 1].

\section{HADS scores}

The HADS is a well-established screening instrument for depression and anxiety in patients with cancer [20, 21]. The HADS has been extensively used in study populations in oncology research, and it is a reliable screening measure in this sensitive patient population [22]. It is a 14-item self-reporting instrument, 2 subscales of 7 items each, namely HADS-Depression and HADSAnxiety, each of which uses a 4-point scale (0: no problems to 3: maximum distress). Thus, scores on each subscale range from 0 to 21 . High scores indicate relatively severe symptoms; the severity of symptoms is interpreted as no (0-7), mild (8-10), moderate (11-14), and high (15-21).

\section{Leisure constraints questionnaire}

Leisure constraints are "factors that are assumed by researchers or perceived or experienced by individuals that limit the formation of leisure preferences or inhibit or prohibit participation and enjoyment in leisure" [23]. In this study, a questionnaire, which was designed to measure the perceived leisure constraints in patients with breast cancer, was developed. Based on the research of Crawford (1991) [17], it assessed 3 discrete types of constraints (intrapersonal, interpersonal, and structural constraints) and measured the severity of each type of constraint. A 5-point Likert rating scale for measuring leisure constraints (from $1=$ completely disagree to $5=$ fully agree) was used to assess the consistency of each of the 20 items. Principal component exploratory factor analysis with the varimax rotation method was used to determine the presence of distinct constraint dimensions in the patients' responses. Originally, 20 items were used to represent 3 types of constraints. Because these 3 dimensions were expected to be almost equally crucial, multiple variables with high loading on each factor were used to enhance the interpretability of results [24]. Items with an eigenvalue of $>1$ and a factor loading of at least .50 were selected for each factor. The reliability of factor dimensions was calculated using the reliability procedure of the SPSS software. The Cronbach method was used to examine the internal consistency of the leisure constraints questionnaire, with the standard value of $>0.70$ reflecting satisfactory internal consistency [25]. The 3 factors were defined as follows: "intrapersonal constraints" ( $\alpha=.95,9$ items), "interpersonal constraints" 
( $\alpha=.92,6$ items), and "structural constraints" ( $\alpha=.88,5$ items). The findings verified the importance of all 3 distinct constraint dimensions. To examine further research issues, we used these 3 factors of perceived leisure constraints. The Chinese version of leisure constraints questionnaire is available upon request.

\section{Procedure}

One of our team members described the study purpose to the patients, obtained their consents, and approached those who met the selection criteria independently. The recruited patients were asked to fill in the questionnaires by themselves. For those who were not capable to carry out the task, the researcher read out the questions and recorded the answers provided by the patients. Also, the researcher was onsite to answer any question raised during the questionnaire administration.

\section{Statistical analyses}

A path coefficient analysis by using multiple regression analysis was conducted to examine the path proposed by Baron and Kenny [26]. We hypothesized that depression mediates the relationship between anxiety and leisure constraints in patients with breast cancer. In the first equation, the mediator (depression) was regressed on the independent variable (anxiety). In the second equation, the dependent variable (leisure constraint) was regressed on the independent variable (anxiety). In the third equation, the dependent variable (leisure constraint) was regressed on the mediator (depression) and the independent variable (anxiety). In addition to these 3 regression equations verifying the relationship among the mediation models, the bootstrapping method was used to examine the reliability of mediating effects [27]. The PROCESS macro for SPSS (version 22) which is specifically written for mediation, moderation, and conditional process analysis, was used to perform mediation analysis [28]. Roles of variables (i.e., independent variable, dependent variable, mediator, moderator, covariate) were provided to the macro and it estimates all the path coefficients, standard errors, $\mathrm{t}$ - and $p$-values, confidence intervals, and other statistics. Further explanations on statistical concepts are described in a recent article published by the authors [29]. The attribution of the independent variable to the dependent variable sustained when the regression model was significant. The hypothesized directions of attribution are shown in Fig. 1. Using 5000 bootstrapped samples generated, the mediating effect was verified when the bootstrapped $95 \%$ confidence intervals of the indirect effect did not include zero.

\section{Results}

\section{Patient characteristics}

In total, 106 patients with breast cancer participated in this study (the response rate was 96.3\%). The demographic characteristics of the patients are listed in Table 1. The disease information of the patients was as follows: $68.9 \%$ were at tumor stage 1 to $2,49.1 \%$ patients had undergone MRM and $43.4 \%$ had undergone BCS, and $78.3 \%$ were receiving chemotherapy at the time of the study.

\section{Descriptive statistics for leisure constraints, anxiety, and depression}

The mean [SD] score of the HADS-anxiety was 5.74 [3.82] (range 0-15), and the proportions of the patients with mild, moderate, and severe anxiety were 62.3, 26.4, and $11.3 \%$, respectively. The mean [SD] score of HADSdepression was 5.36 [3.52] (range 0-17), and the proportions of the patients with mild, moderate, and severe depression were $77.4,12.2$, and $10.4 \%$, respectively. The factor loadings of each of the 3 factors measured using the leisure constraints questionnaire are presented in Table 2. The average scores divided by the number of items in intrapersonal, interpersonal, and structural constraints were $2.61,2.29$, and 2.62, respectively; thus, structural constraints were the most crucial factor. The global leisure constraint score was 50.06 [16.32], indicating that this constraint exerted an effect of "moderate" intensity on the patients with breast cancer (Table 3).

\section{Mediating effects of depression on anxiety and leisure constraints}

To examine if cancer staging plays a role in the mediating effects, we conducted the analyses in all patients, patients with earlier cancer stages (stage 0,1 , or 2 ), and patients with advanced cancer stages (stage 3 or 4 ).

The results for all patients are summarized in Table 4 . The first step was to determine whether the presumed mediator (depression) and predictor (anxiety) were associated. The results indicated that anxiety was significantly associated with depression $(\beta=0.69, P<001)$. The second step involved regressing the outcome variable (leisure constraints) on the presumed mediator (depression). Depression was significantly associated with leisure constraints $(\beta=0.48, P<001)$. Testing for mediation was the third step, and it involved regressing the outcome variable (leisure constraints) on the predictor (anxiety). Anxiety was significantly associated with leisure constraints $(\beta=0.45, P<.001)$. The final step involved regressing leisure constraints on both the predictor (anxiety) and the presumed mediator (depression). The strength of each relationship is shown in Fig. 1. The predictor-outcome relationship must be not significant and the mediator-outcome relationship must be significant to sustain a complete mediation model. When depression was controlled, the previously significant relationship between the predictor (anxiety) and the outcome (leisure constraints) became non-significant 


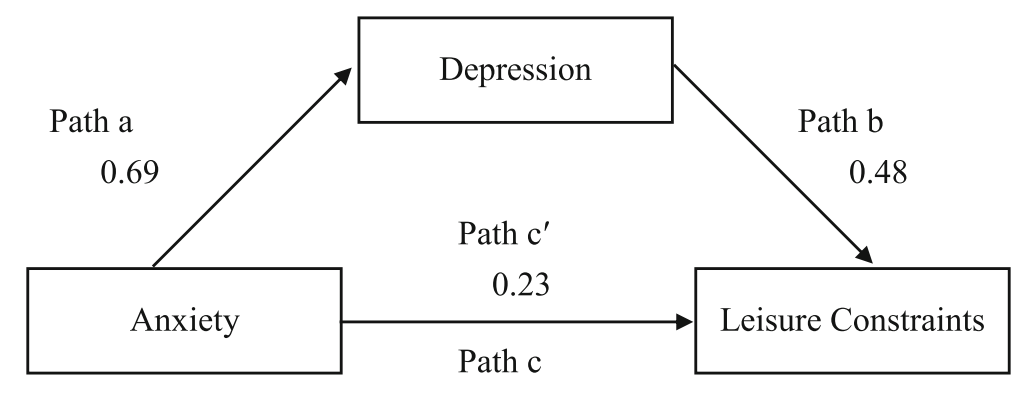

0.45

Fig. 1 Testing the Mediating Effect on Leisure Constraints

( $\beta=0.23, P=.051)$. On the other hand, the mediatoroutcome relationship was significant. These met the mediation theoretical requirement. The accelerated bootstrapping confidence intervals of the indirect effect did not include zero (0.276 to 1.663$)$, indicating that the model was reliable and that depression completely mediated the effects of anxiety on leisure constraints.

Table 1 Characteristics of the Study Patients $(n=106)$

\begin{tabular}{|c|c|c|}
\hline Variables & n (\%) & Mean (SD), Range \\
\hline Age (years) & & $52.48(9.17), 25-74$ \\
\hline \multicolumn{3}{|l|}{ Marital status } \\
\hline Married & $87(82.1)$ & \\
\hline Unmarried & $8(7.5)$ & \\
\hline Others & $11(10.4)$ & \\
\hline \multicolumn{3}{|l|}{ Religion } \\
\hline No & $10(9.4)$ & \\
\hline Yes & $96(90.6)$ & \\
\hline \multicolumn{3}{|l|}{ Tumor stage } \\
\hline Stage 0 & $10(9.4)$ & \\
\hline Stage 1-2 & $73(68.9)$ & \\
\hline Stage 3-4 & $23(21.7)$ & \\
\hline \multicolumn{3}{|l|}{ Surgery } \\
\hline BCS & $46(43.4)$ & \\
\hline MRM & $52(49.1)$ & \\
\hline$M R M+I B R$ & $8(7.5)$ & \\
\hline \multicolumn{3}{|c|}{ Chemotherapy received until now } \\
\hline No & $23(21.7)$ & \\
\hline Yes & $83(78.3)$ & \\
\hline \multicolumn{3}{|c|}{ Radiation received until now } \\
\hline No & $43(40.6)$ & \\
\hline Yes & $63(59.4)$ & \\
\hline \multicolumn{3}{|c|}{ Hormone therapy received until now } \\
\hline No & $52(49.1)$ & \\
\hline Yes & $54(50.9)$ & \\
\hline
\end{tabular}

The results for subjects with earlier cancer stage are summarized in Table 5. Testing step 1 indicated that anxiety was significantly associated with depression $(\beta=$ $0.61, P<001)$ and testing step 2 indicated that depression was significantly associated with leisure constraints $(\beta=0.46, P<001)$. Testing for mediation at the third step indicated that anxiety was significantly associated with leisure constraints $(\beta=0.43, P<001)$. The final step involved regressing leisure constraints on both anxiety and depression. When depression was controlled, the previously significant relationship between the anxiety and leisure constraints became non-significant $(\beta=0.24$, $P=051$ ). On the other hand, the mediator-outcome relationship was significant. The accelerated bootstrapping confidence intervals of the indirect effect did not include zero (0.234 to 1.595$)$, indicating that the model was reliable and that depression completely mediated the effects of anxiety on leisure constraints.

The results for subjects with advanced cancer stages are summarized in Table 6 . Testing step 1 indicated that anxiety was significantly associated with depression $(\beta=$ $0.88, P<001)$ and testing step 2 indicated that depression was significantly associated with leisure constraints $(\beta=0.60, P=.002)$. Testing for mediation at the third step indicated that anxiety was significantly associated with leisure constraints $(\beta=0.59, P=0.003)$. At the final step, when depression was controlled, the previously significant relationship between the anxiety and leisure constraints became non-significant $(\beta=0.26, P=0.50)$. In contrast with previous analyses, the mediatoroutcome relationship was not significant. The accelerated bootstrapping confidence intervals of the indirect effect included zero ( -0.729 to 3.971$)$, indicating that the model was non-reliable.

\section{Discussion}

To our knowledge, this is the first study that investigates leisure constraints in patients with breast cancer. Treatment of diseases is now possible owing to advancements in medical technology; however, patients with cancer require treatment as well as an improvement in their 
Table 2 Leisure Constraints Dimension from Factor Analysis

\begin{tabular}{|c|c|c|c|}
\hline \multirow[t]{2}{*}{ Factors/ltems } & \multirow{2}{*}{$\begin{array}{l}\text { Factor } 1 \\
\text { Intrapersonal }\end{array}$} & \multirow{2}{*}{$\begin{array}{l}\text { Factor } 2 \\
\text { Interpersonal }\end{array}$} & \multirow{2}{*}{$\begin{array}{l}\text { Factor } 3 \\
\text { Structural }\end{array}$} \\
\hline & & & \\
\hline 17. Unstable health condition & .840 & & \\
\hline 18. I am so unwell & .832 & & \\
\hline 20. Fear of infection & .777 & & \\
\hline 16. Fear of increasing burden on others & .751 & & \\
\hline 19. Physical appearance change & .738 & & \\
\hline 11. Physical symptoms & .722 & & \\
\hline 14. Cannot relieve symptoms & .707 & & \\
\hline 9. Lack of entertainment information & .571 & & \\
\hline 10. No time & .562 & & \\
\hline 1. It is not necessary & & .815 & \\
\hline 3. Personality & & .814 & \\
\hline 4. Lack of experience and skills & & .743 & \\
\hline 2. Fear of being injured during activities & & .739 & \\
\hline 13. No one is engaged with me & & .614 & \\
\hline 12. No family support & & .576 & \\
\hline 15. No sufficient financial support & & & .555 \\
\hline 8. Lack of transportation & & & .501 \\
\hline 5. Not enough space and facilities & & & .829 \\
\hline 6. Not suitable leisure facilities & & & .827 \\
\hline 7. Leisure places are too crowded & & & .654 \\
\hline Eigenvalue & 11.963 & 1.426 & 1.088 \\
\hline Variance Explained & 59.817 & 7.131 & 5.438 \\
\hline Cumulative Variance & 59.817 & 66.948 & 72.386 \\
\hline Scale Mean Score & 2.61 & 2.29 & 2.62 \\
\hline
\end{tabular}

Table 3 Summary of Questionnaire Responses of the Patients with Breast Cancer $(n=106)$

\begin{tabular}{llcc}
\hline Variables & $\mathrm{n}(\%)$ & Mean (SD) & Range \\
\hline HADS-Anxiety & $66(62.3)$ & $5.74(3.82)$ & $0-15$ \\
Mild (0-7 points) & $28(26.4)$ & & \\
Moderate (8-10 points) & $12(11.3)$ & & \\
Severe (11-21 points) & & $5.36(3.52)$ & $0-17$ \\
HADS- Depression & $82(77.4)$ & & .76 \\
Mild (0-7 points) & $13(12.2)$ & & \\
Moderate (8-10 points) & $11(10.4)$ & $50.06(16.32)$ & .96 \\
Severe (11-21 points) & & $23.45(8.13)$ & .94 \\
LCQ-Leisure constraints & & $13.75(4.59)$ & .90 \\
Intrapersonal constraints (9 items) & & $13.09(4.60)$ & .92 \\
Interpersonal constraints (6 items) & & \\
Structural constraints (5 items) & & \\
\hline
\end{tabular}


Table 4 Mediating Effect of Depression between Anxiety and Leisure Constraints in All Cancer Patients $(n=106)$

\begin{tabular}{|c|c|c|c|c|c|}
\hline Testing steps in mediation model & $\mathrm{t}$ & B & $\beta$ & $R^{2}$ & $P$-value \\
\hline \multicolumn{6}{|l|}{ Testing step 1 (path a) } \\
\hline to Mediator & 9.78 & 0.77 & 0.69 & 0.48 & $<.0001$ \\
\hline \multicolumn{6}{|l|}{ Testing step 2 (path b) } \\
\hline to Outcome & 5.60 & 2.29 & 0.48 & 0.23 & $<.0001$ \\
\hline \multicolumn{6}{|l|}{ Testing step 3 (path c) ${ }^{k}$} \\
\hline to Outcome & 5.19 & 0.11 & 0.45 & 0.20 & $<.0001$ \\
\hline \multicolumn{6}{|l|}{ 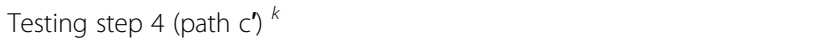 } \\
\hline to Outcome & 1.97 & 0.99 & 0.23 & 0.26 & .051 \\
\hline Mediator & 2.73 & 1.53 & 0.32 & & .007 \\
\hline
\end{tabular}

$B$ estimates represent the regression coefficient

quality of life. Maintaining regular leisure habits and promoting physical activity are part of the pursuit of improving the quality of life among patients with cancer. However, patients with cancer encounter physical and psychological distress, which may lead to the loss of selfcare ability and confidence in the pursuit of leisure. Patients with breast cancer experience multiple symptoms associated with the disease and its treatment. Two commonly observed psychology symptoms (anxiety and depression) and leisure constraints in patients with breast cancer were selected for analysis in this study. Notably, this study demonstrated that anxiety, leisure constraints, and depression are interrelated in the patients with breast cancer and that depression mediates the relationship between anxiety and leisure constraints. Furthermore, we found that depression completely mediated the effects of anxiety on leisure constraints in patients with earlier cancer stages but not in patients with advanced cancer stages.

Anxiety is the most common psychological distress in patients with breast cancer [30,31]. Although the high

Table 5 Mediating Effect of Depression between Anxiety and Leisure Constraints in Early Cancer Stages $(n=83)$

\begin{tabular}{|c|c|c|c|c|c|c|}
\hline \multicolumn{2}{|c|}{ Testing steps in mediation model } & $\mathrm{t}$ & $\mathrm{B}$ & $\beta$ & $R^{2}$ & $P$-value \\
\hline \multicolumn{7}{|c|}{ Testing step 1 (path a) } \\
\hline Predictor & to Mediator & 6.89 & 0.52 & 0.61 & 0.37 & $<.0001$ \\
\hline \multicolumn{7}{|c|}{ Testing step 2 (path b) } \\
\hline Mediator & to Outcome & 4.60 & 2.48 & 0.46 & 0.21 & $<.0001$ \\
\hline \multicolumn{7}{|c|}{ Testing step 3 (path c) ${ }^{k}$} \\
\hline Predictor & to Outcome & 4.28 & 2.00 & 0.43 & 0.18 & $<.0001$ \\
\hline \multicolumn{7}{|c|}{ Testing step 4 (path c) ${ }^{k}$} \\
\hline Predictor & to Outcome & 1.98 & 1.13 & 0.24 & 0.24 & .051 \\
\hline Mediator & & 2.51 & 1.68 & 0.31 & & .014 \\
\hline
\end{tabular}

Table 6 Mediating Effect of Depression between Anxiety and Leisure Constraints in Advanced Cancer Stages $(n=23)$

\begin{tabular}{llllll}
\hline Testing steps in mediation model & $\mathrm{t}$ & $\mathrm{B}$ & $\beta$ & $\mathrm{R}^{2}$ & $P$-value \\
\hline $\begin{array}{l}\text { Testing step 1 (path a) } \\
\text { Predictor to Mediator }\end{array}$ & 8.57 & 0.86 & 0.88 & 0.78 & $<.0001$ \\
$\begin{array}{l}\text { Testing step 2 (path b) } \\
\text { Mediator to Outcome }\end{array}$ & 3.44 & 1.88 & 0.60 & 0.36 & .002 \\
$\begin{array}{l}\text { Testing step 3 (path c) } \\
\text { Predictor to Outcome }\end{array}$ & 3.31 & 1.79 & 0.59 & 0.34 & .003 \\
$\begin{array}{l}\text { Testing step 4 (path c) }{ }^{k} \\
\text { Predictor to Outcome }\end{array}$ & 0.68 & 0.78 & 0.26 & 0.37 & .50 \\
Mediator & 1.00 & 1.18 & 0.38 & & .33 \\
\hline
\end{tabular}

$B$ estimates represent the regression coefficient

prevalence of anxiety symptoms in patients with breast cancer is known, the influence of anxiety disorders on cancer prognosis have been relatively less studied compared with the impact of depression. In studies on patients with chronic diseases, anxiety disorders were closely associated with increased health care use, decreased physical well-being, and increased physical disability [32]. In addition, the mechanism underlying anxiety or depression should be considered among the toxic side effects of relevant treatments. Patients may experience difficulties in participating in physical activities [8].

Inactivity adversely affects the symptoms and survival rate of patients with cancer. Psychology, accessibility, time, partners, and security factors can all become crucial leisure constraints [33]. Stressors may influence anxiety through its effect on satisfaction with leisure activities [34]. Regular leisure activities can mitigate stress and depression [35]. In this study, intrapersonal constraints involved "individual psychological states and attributes;" the primary intrapersonal constraints were unstable health condition, fear of increasing burden on others, changes in physical appearance, and the effects of symptoms. Interpersonal constraints were "the result of interpersonal interactions or relationships between individuals' characteristics;" the chief interpersonal constraints were a patient's personality, absence of the need for leisure, lack of family support, and lack of friends who are engaged in similar activities. Clearly, social relationships played a major role in shaping leisure activities. Family relationships impinged on some people's freedom to participate in activities, but the lack of relationships prevented others from engaging in activities that they previously enjoyed [18]. Structural constraints were "intervening factors between leisure preference and participation;" the major structural constraints were insufficient financial support, lack of transportation, and unsuitable leisure facilities. Constraints that were 
assumed to play an intervening role in the leisure preference-participation relationship were considered "only one of the ways in which barriers may be associated with preferences and participation" [16]. They also noted that these constraints might be interrelated. Leisure benefits were derived from spiritual experience, spiritual wellbeing, and spiritual coping with stress. A study reported leisure factors that produce spiritual benefits [36]. Consistent with the findings of other studies [19, 33, 37], we also found that structural constraints were the most crucial constraints, followed by intrapersonal and interpersonal constraints. The item "no time for leisure" usually belongs to structural constraints; however, in the present study, this item was placed under intrapersonal constraints. Hence, the patients with breast cancer did not actually have insufficient time, but rather perceived that they had insufficient time. This indicates that leisure constraints in patients with breast cancer in this study were affected by psychological factors. The illness might have bright down their spirit to interpret self and the world in a negative way which is common across populations [38].

The symptoms of breast cancer experienced during treatment affect many women and their partners as they attempt to resume functional activities and crucial life roles during early survivorship. Disruptions in these valued activities and roles may affect the health and wellbeing of patients and their partners during and after early survivorship [39]. Successful participation in meaningful activities and roles can significantly improve health benefits, including a decrease in stress and anxiety levels. Conversely, strategies that effectively reduce anxiety and depression can also reduce leisure constraints in patients with breast cancer and increase their motivation to participate in leisure activities. The long-term consequences of activity limitations and role restrictions have been associated with serious health concerns, including physiological changes, depression, and anxiety, which lead to chronic diseases and poor quality of life [40, 41]. The present study showed that anxiety can further increase leisure constraints through depression. We should develop interventions to resolve psychological distress so that patients can resume leisure activities more effectively and improve their quality of life as soon as possible.

This study has a few limitations. First, because of the cross-sectional design of the study, changes in symptoms over time were not investigated. Replications and additional longitudinal studies that focus on changes in relationships among these symptoms over time are warranted. Certainly, it is possible that those with high depression and anxiety levels might had already perceived that their leisure time was limited even before they had a cancer diagnosis. The role of a such preexisting psychiatric symptoms require further investigation. Second, the current mediation modeling approach did not concern possible confounders. Newer research into the areas of mediation and moderation [42] or alternative models such as the Rubin's causal model may be used to establish the possible mediation and confounding paths [43] and brought forth a more modern understanding of those phenomena [42]. Third, this study enrolled patients with breast cancer who were likely to be in a relatively stable condition. Therefore, seriously ill patients were not represented in this study, and the results of this study may not be generalizable to that population. Moreover, this study was limited by its small sample size. Additional studies may need to be replicated using a larger sample. Any conclusion from this study may be tentative; nevertheless, these results may provide useful insights for future research.

\section{Conclusions}

This study demonstrated that anxiety, leisure constraints, and depression are interrelated in the patients with breast cancer and that depression completely mediates the relationship between anxiety and leisure constraints in patients with earlier cancer stages but not in patients with advanced cancer stages. The current findings are clinically crucial because they indicate the need to consider the simultaneous management of patient anxiety and depression, because the simultaneous resolution of the symptoms of emotional distress may alleviate leisure constraints while enhancing the willingness to participate in leisure activities.

\section{Supplementary information}

Supplementary information accompanies this paper at https://doi.org/10. 1186/s12905-019-0838-7.

Additional file 1. Leisure constraints questionnaire. English translation of the Chinese version of leisure constraints questionnaire. The Chinese version is available upon request.

\section{Abbreviations}

BCS: Breast-conserving surgery; HADS: Hospital Anxiety and Depression Scale; IBR: Immediate breast reconstruction; LCQ: Leisure Constraints

Questionnaires; MRM: Modified radical mastectomy

\section{Acknowledgements}

We are grateful for the Taipei Medical University of Taiwan for its support of this study for editing (grant no.TMU106-AE1-B13) and the company, Wallace Academic Editing, for assisting this article. The authors thank all the participates for their assistance and contribution to this research.

\section{Authors' contributions}

$\mathrm{HM}$ collected, data entry and interpreted the data; JH interpreted the data and drafted the article; TW review study design, writing the result section, and revised the manuscript. All authors have read and approved the manuscript.

Funding

No funding was obtained for this study.

Availability of data and materials

The data sets used and analyzed during the current study are available from the corresponding author on reasonable request. 


\section{Ethics approval and consent to participate}

The institutional review board of the Chia-Yi Christian Hospital, Taiwan, approved the project proposal prior to the initiation of the study [CYCH-IRB 102060]. Written consents were obtained from the participants.

\section{Consent for publication}

Not applicable.

\section{Competing interests}

The authors declare that they have no competing interests.

\section{Author details}

'Department of Nursing, Ditmanson Medical Foundation Chia-Yi Christian Hospital, Chia-Yi, Taiwan. ${ }^{2}$ Department of Internal Medicine, Erlin Christian Hospital, ChangHua, Taiwan. ${ }^{3}$ School of Nursing, College of Nursing, Taipei Medical University, Taipei, Taiwan. ${ }^{4}$ Cochrane Taiwan, Taipei Medical University, Taipei, Taiwan.

Received: 25 February 2019 Accepted: 7 November 2019

Published online: 20 November 2019

\section{References}

1. Rosenberg SM, Newman LA, Partridge AH. Breast cancer in young women: rare disease or public health problem? J Am Med Assoc Oncol. 2015;1:877-8.

2. Ministry of Health and Welfare, Taiwan. Main causes of death 2016. https:// www.mohw.gov.tw/cp-16-33598-1.html. Accessed January 17, 2019.

3. American Cancer Society. Breast Cancer: Facts \& Figures 2017-2018. https:// www.cancer.org/content/dam/cancer-org/research/cancer-facts-andstatistics/breast-cancer-facts-and-figures/breast-cancer-facts-and-figures-201 7-2018.pdf. Accessed January 17, 2019.

4. Moulder S, Hortobagyi GN. Advances in the treatment of breast cancer. Clin Pharmacol Ther. 2008:83:26-36

5. Maass SW, Roorda C, Berendsen AJ, Verhaak PF, de Bock GH. The prevalence of long-term symptoms of depression and anxiety after breast cancer treatment: a systematic review. Maturitas. 2015;82:100-8.

6. Burgess C, Cornelius V, Love S, Graham J, Richards M, Ramirez A. Depression and anxiety in women with early breast cancer: five year observational cohort study. BMJ. 2015;26:330

7. Kissane DW, Grabsch B, Love A, Clarke DM, Bloch S, Smith GC. Psychiatric disorder in women with early stage and advanced breast cancer: a comparative analysis. Aust N Z J Psychiatr. 2004;38:320-6.

8. Park EM, Gelber S, Rosenberg SM, et al. Anxiety and depression in young women with metastatic breast Cancer: a cross-sectional study. Psychosomatics. 2018;59:1-8.

9. Hjerl K, Andersen EW, Keiding N, Mouridsen HT, Mortensen PB, Jørgensen T. Depression as a prognostic factor for breast cancer mortality Psychosomatics. 2003:44:24-30

10. Watson M, Homewood J, Haviland J, Bliss JM. Influence of psychological response on breast cancer survival: 10-year follow-up of a population-based cohort. Eur J Cancer. 2005;41:1710-4.

11. McTiernan A. Weight, physical activity and breast cancer survival. Proc Nutr Soc. 2018:77:1-9.

12. Lahart IM, Metsios GS, Nevill AM, Carmichael AR. Physical activity for women with breast cancer after adjuvant therapy. Cochrane Database Syst Rev. 2018;29:1.

13. Penedo FJ, Dahn JR. Exercise and well-being: a review of mental and physical health benefits associated with physical activity. Curr Opin Psychiatr. 2005;18:189-93.

14. Sheikh MA, Vancampfort D, Stubbs B. Leisure time physical activity and future psychological distress: a thirteen year longitudinal population-based study. J Psychiatr Res. 2018;101:50-6.

15. Yan AF, Wang Y, Ng AV. Physical activity and annual medical outlay in U.S. colorectal, breast and prostate cancer survivors. Prev Med Rep. 2018;9:118-23.

16. Crawford DW, Godbey G. Reconceptualizing barriers to family leisure. Leis Sci. 1987;9:119-27.

17. Crawford DW, Jackson EL, Godbey G. A hierarchical model of leisure constraints. Leis Sci. 1991;13:309-20

18. Samdahl DM, Jekubovich NJ. A critique of leisure constraints: comparative analyses and understandings. J Leis Res. 1997;29:430-52.

19. Liu $\mathrm{H}$. Walker $\mathrm{GJ}$. The effects of urbanization, motivation, and constraints on Chinese people's leisure-time physical activity. Leis Sci. 2015;37:458-78.
20. Chen PY, See LC, Wang CH, Lai YH, Chang HK, Chen ML. The impact of pain on the anxiety and depression of cancer patients. Formos J Med. 1999:3:373-82

21. Zigmond AS, Snaith RP. The hospital anxiety and depression scale. Acta Psychiatr Scand. 1983;67:361-70.

22. Bjelland I, Dahl AA, Haug TT, Neckelmann D. (2002) the validity of the hospital anxiety and depression scale. An updated literature review. J Psychosom Res. 2002;52:69-77.

23. Jackson EL. Will research on leisure constraints still be relevant in the twenty-first century? J Leis Res. 2000;32(1):62-8.

24. Costello AB, Osborne JW. Best practices in exploratory factor analysis: four recommendations for getting the most from your analysis. Pract Assess Res Eval. 2005;10:1-9.

25. Tavakol M, Dennick R. Making sense of Cronbach's alpha. Int J Med Educ. 2011;2:53-5

26. Shrout PE, Bolger N. Mediation in experimental and nonexperimental studies: new procedures and recommendations. Psychol Methods. 2002;7:422-45.

27. Baron $R$, Kenny $D$. The moderator-mediator variable distinction in social psychological research: conceptual, strategic, and statistical considerations. J Pers Soc Psychol. 1986;51:1173-82.

28. Preacher KJ, Hayes AF. SPSS and SAS procedures for estimating indirect effects in simple mediation models. Behav Res Methods Instrum Comput. 2004:36:717-31

29. Hayes AF, Montoya AK, Rockwood NJ. The analysis of mechanisms and their contingencies: PROCESS versus structural equation modeling. AMJ. 2017;25:76-81.

30. Salvo $N$, Zeng $L$, Zhang $L$, et al. Frequency of reporting and predictive factors for anxiety and depression in patients with advanced cancer. Clin Oncol. 2012;24:139-48.

31. Brintzenhofe-Szoc KM, Levin TT, Li Y, Kissane DW, Zabora JR. Mixed anxiety/ depression symptoms in a large cancer cohort: prevalence by cancer type. Psychosomatics. 2009;50:383-91.

32. Roy-Byrne PP, Davidson KW, Kessler RC, et al. Anxiety disorders and comorbid medical illness. Gen Hosp Psychiatry. 2008;30:208-25.

33. Oh SS, Oh SY, Caldwell LL. The effects of perceived leisure constraints among Korean university students. In: Todd, Sharon, comp, ed. 2002. Proceedings of the 2001 northeastern recreation research symposium. Gen. Tech. Rep. NE-289. Newtown Square, PA: U.S. Department of Agriculture, Forest Service, Northeastern Research Station. 2002:183-187.

34. Romero-Moreno R, Losada A, Márquez-González M, Mausbach BT. Stressors and anxiety in dementia caregiving: multiple mediation analysis of rumination, experiential avoidance, and leisure. Int Psychogeriatr. 2016;28:1835-44.

35. Mikkelsen SS, Tolstrup JS, Flachs EM, Mortensen EL, Schnohr P, FlensborgMadsen T. A cohort study of leisure time physical activity and depression. Prev Med. 2010;51:471-5.

36. Heintzman P. The spiritual benefits of leisure. Leisure/Loisir. 2010:33:419-45.

37. Brown PR, Brown WJ, Miller YD, Hansen V. Perceived constraints and social support for active leisure among mothers with young children. Leis Sci. 2010;23:131-44.

38. Trick L, Watkins $E$, Windeatt $S$, Dickens $C$. The association of perseverative negative thinking with depression, anxiety and emotional distress in people with long term conditions: a systematic review. J Psychosom Res. 2016;91:89-101.

39. Keesing S, Rosenwax L, McNamara B. The implications of women's activity limitations and role disruptions during breast cancer survivorship. Women Health. 2018;14:1745505718756381. https:/doi.org/10.1177/1745505718756381.

40. Yoon NH, Lee HY, Kwak MS, et al. Comparison of satisfaction with cancer screening at mobile van and static sites: national cancer screening program in Korea. Jpn J Clin Oncol. 2009:39:169-74.

41. Bairati I, Turcotte S, Doray G, Belleau F, Grégoire L. Development and validation of an instrument assessing women's satisfaction with screening mammography in an organized breast cancer screening program. BMC Health Serv Res. 2014:14:9.

42. Kraemer HC, Kiernan M, Essex M, Kupfer DJ. How and why criteria defining moderators and mediators differ between the Baron \& Kenny and MacArthur approaches. Health Psychol. 2008;27(2 Suppl):S101-8.

43. Rubin D. Estimating causal effects of treatments in randomized and nonrandomized studies. J Educ Psychol. 1974;66:688-701.

\section{Publisher's Note}

Springer Nature remains neutral with regard to jurisdictional claims in published maps and institutional affiliations. 